\title{
THE ICONICITY AND EASE OF LEARNING OF PICTURE COMMUNICATION SYMBOLS: A STUDY WITH AFRIKAANS-SPEAKING CHILDREN
}

\author{
Magdel Basson and Erma Alant
}

Centre for Augmentative and Alternative Communication

University of Pretoria

\begin{abstract}
Graphic symbols form an important part of most augmentative and alternative communication (AAC) users' communication systems. Studies focusing on the way different graphic symbols are learned and retained are pivotal for a better understanding of the processes involved. The current study set out to determine how accurately typically developing urban, 6-year-old Afrikaans-speaking children could identify 16 Picture Communication Symbols ${ }^{\mathrm{MM}}$ (PCS) presented thematically on a communication overlay, and also how accurately they could recognize these symbols following exposure to a learning experience. Participants, divided into two cohorts, were presented with a 16-matrix overlay and required to match symbols with spoken Afrikaans labels. They were then divided into two groups, one group receiving training in the meaning of the symbols and the other group receiving no training. Finally the test-procedure was repeated. Results indicated that the 16 PCS ${ }^{\mathrm{TM}}$ symbols had an iconicity of $12.5 \%$ (accuracy score $>50 \%$ ), and that there was a significant improvement in both the experimental and the control groups' post-test results.
\end{abstract}

Key words: Augmentative and alternative communication, communication overlay, iconicity, learnability, ${ }^{1}$ Picture Communication Symbols (PCS) ${ }^{\mathrm{IM}}$, recognition

\section{INTRODUCTION}

Augmentative and alternative communication (AAC) refers to those strategies that can be used to supplement the existing communication of an individual with little or no functional speech (LNFS). Although these strategies span the use of a broad range of aided and unaided methods, graphic symbols form a very important part of most AAC systems. Even for those AAC users utilising unaided systems, access to an aided system, be it pictographic or arbitrary (traditional orthography) in nature, will form an important part of their communication system.

When selecting an appropriate symbol set/system for AAC users, iconicity is one of the variables to consider (Fuller \& Lloyd, 1997). Iconicity is a general term referring to the visual relationship between a symbol and its referent (Blischak, Lloyd \& Fuller, 1997; Fuller \& Lloyd, 1991). The iconicity of a symbol can be described in two ways. Transparency describes the guessability of a symbol in the absence of its referent, while translucency refers to the degree to which individuals perceive a relationship between a symbol and its referent when the referent is known (Blischak et al., 1997).

The iconicity hypothesis postulated by Fristoe and Lloyd (1979) states that the visual representation afforded by some AAC symbols may facilitate the learning and memory of symbol referent associations. Fuller and Stratton (1991) explained that symbols with a strong relationship to their referents would be easier to learn and remember than symbols with a weak relationship. According to Fuller and Lloyd (1997) research-done with aided and unaided symbols have supported this iconicity hypothesis, with more translucent/transparent sets/systems being easier to learn and recall than less translucent/transparent sets/ systems (Clark, 1981; Mizuko, 1987; Mizuko \& Reichle, 1989).

Iconicity can also be defined as the degree to which an individual perceives visual similarity between a symbol and its referent (Blischak, Lloyd \& Fuller, 1997; Huer \& Saenz, 2002).

${ }^{\mathrm{P}} \mathrm{PCS}^{\mathrm{TM}}$ is a Mayer-Johnson product.
The investigation of visual perception and cross-cultural differences in the perception of pictorial materials, thus the iconicity for a given viewer (Haupt \& Alant, 2002), indicated factors that could influence this perception (Deregowski, 1980; Duncan, Gourlay \& Hudson, 1973; Miller, 1973). Some of the factors discussed in the literature are: schooling (Duncan, Gourlay \& Hudson, 1973; Martlew \& Connolly, 1996), material on which the symbols are printed (Deregowski, 1980) and previous experience with symbols (DeLoache, 1991; Duncan et al., 1973; Miller, 1973; Stephenson \& Linfoot, 1996).

To date, most iconicity studies have been done within European-American linguistic communities (Huer, 2000). It however, cannot be taken for granted that results obtained from iconicity studies on one group of people can be generalized to another (Haupt \& Alant, 2002). While a literate communication partner can read the accompanying gloss (written text), a communication partner who cannot read, has to rely on symbol iconicity to guess the symbol's meaning. Iconicity of symbols becomes particularly important in populations where a large percentage of people might be unable to read, as for example, in South Africa. People's interpretations on first exposure to graphic symbols can significantly facilitate interaction within a particular population group. Iconicity (first exposure or transparency) is, howèver, not the only important variable when choosing a symbol set/system. The ease with which a symbol set/system can be learned (learnability) is also important, as most symbols will not be totally transparent or translucent. Haupt and Alant (2002) investigated the iconicity of selected PCS in the context of a South African culture. They found that the 36 symbols they presented to rural Zulu-speaking participants had a generally low average iconicity of between $2.8 \%$ (iconicity values $\geq 75 \%$ ) and $11.1 \%$ (iconicity values $\geq 50 \%$ ). Although iconicity is an important issue in symbol learning, ease of learning is an important additional issue that needs to be addressed when deciding on a specific graphic symbol set or system. Studies should therefore not only look at the responses of individuals at first exposure, but also at learnability. Learnability can be defined as the ease with 
which a symbol can be learned by an AAC user or the individual communicating with the AAC user (Basson, 2004). The current study will strengthen the understanding of issues relating to iconicity in different cultural groups, by investigating the iconicity of selected PCS symbols for Afrikaans-speaking children. Afrikaans is spoken by $14.4 \%$ of the South African population, the third most spoken home language in South Africa (Orkin, 1998). This investigation into the way in which Afrikaans-speaking children relate to PCS symbols could yield important information for the use of PCS symbols to facilitate symbol learning and use. The study will further extend our knowledge about PCS symbols, by describing the ease of learning for this group of children and by comparing two groups' pre-and-post performances: group one after being exposed to a single learning experience and group two, the control group, without exposure to training.

\section{METHOD}

\section{Aims}

The main aim of this study was to determine how accurately typically developing urban, 6-year-old Afrikaans-speaking children could firstly, identify 16 Picture Communication Symbols (PCS) presented thematically on a commercially available communication overlay, and, secondly, recognize these symbols following exposure to a learning experience.

\section{Sub-aims}

The three sub-aims were as follow:

1. To determine how accurately 6-year-old Afrikaans-speaking children were able to select the correct symbol in response to its spoken label.

2. To determine how accurately the experimental and control groups were able to select the correct symbol in response to its spoken label, after the experimental group received a training session.

3. To compare the pre- and post-test data between groups, to see whether,significant differences exist.

\section{Research Design}

A quasi-experimental control group design (McMillan \& Schumacher, 2001) was used. Forty-six learners with Afrikaans as mother tongue were exposed to 16 PCS symbols presented on an overlay. In response to a verbal Afrikaans label, the participants were required to select the symbol they thought depicted that concept the best. The participants were then randomly divided into an experimental and a control group. The experimental group received one session's training in the meaning of the symbols whilst the control group was exposed only to the pre and post testing situations.

\section{Participants}

\section{Selection criteria}

Participants had to be learners between the ages of $6 ; 0$ [years; months] and 6;11, with Afrikaans as mother-tongue. There had to be no history of developmental delay; apparent learning problems; hearing loss or uncorrected eyesight. All participants were in Grade $R$ classes and had been enrolled in preschool for at least 6 months prior to the commencement of the study. The participants had no previous experience with PCS symbols.

\section{Sampling procedure}

The study was conducted in the northern part of the Free State province of South Africa. A list of pre-schools in the participating district was obtained from the First Education Specialist (FES) for Early Childhood Development (ECD) in the district. There were seven schools with Afrikaans as the medium of instruction. Six schools in close proximity were approached and four agreed to participate in the study. Forty-six learners ( 25 girls and 21 boys) who met the requirements of the selection criteria participated in the study $(\mathrm{M}=6 ; 5)$.

\section{Material}

\section{Testing material}

This study was partially based on a study by Haupt (2001; Haupt \& Alant, 2002). In her study Haupt (2001) used a commercially available 36 -matrix communication overlay to investigate the iconicity of 36 PCS symbols for a population of Zuluspeaking 10-year-olds. The symbols on the communication overlay used in Haupt's study were thematically organized around the bed-making theme. The current study differed from Haupt's in three ways: apart from iconicity, learnability was also investigated; the populations of the two studies differed in age and culture; and the current study utilized a 16-matrix overlay. During the study, two overlays, the test overlay and the pre-test training overlay, were used. Because of the age of the participants it was decided to reduce the number of symbols on the overlay from 36 to 16 (Basson, 2004). The researcher was unable to find a published 16-matrix overlay for bed-making. To maintain the theme it was decided to compile a 16-matrix bed-making overlay.

The process of compiling this overlay is described. Seven commercially available 16-matrix overlays were randomly selected and studied to determine which symbols were common to these overlays. Three symbols 'let me'; 'no'; and 'uh oh' were present on six of the seven displays studied and were placed in a pool of probable symbols to be used on the overlay. The next step was to view published commercially available 9-matrix overlays, developed by Elder and Goossens (1996) for moderately/severely developmentally delayed adolescents and adults. Two of these overlays were organized around the bed-making theme: "Stripping the bed" and "Making the bed". There were four symbols present on both overlays, 'What a mess!'; 'Help me, please.'; 'Need to pull it.'; and 'Let's get the bed made' which were also placed in the pool. Ten symbols: 'They're dirty.'; 'Need to change them.'; 'Let's take it off.'; 'Put it in the hamper.'; 'Thank you.'; 'It's crooked.'; 'Have to fold it back.'; 'Got to tuck it in.'; 'Let's put it on...'; and 'Looks good.' were left on the two 9matrix overlays. The addition of these 10 symbols to the pool brought the total to 17 , one more symbol than required. All 17 symbols were translated from English to Afrikaans. During the translation process, the translators were unable to reach consensus about the term 'Let's put it on...' and this symbol was consequently removed from the pool and the remaining 16 symbols were placed on the communication overlay (Basson, 2004).

The purpose of the pre-test training overlay was to explain the matching task to the participants. They were also given the opportunity to practise the task. It was important that the participants be familiar with the pictures used on the overlay. Ten pictures used by Haupt (2001) on her pre-test training overlay were used. A further six pictures were drawn from a corpus of pictures familiar to the age group (Basson, 2004). The order of presentation on the pre-test overlay as well as the order of presentation during the test procedure was randomly drawn from a hat. 
The material used for the pre- and post-tests were translated from the original English into Afrikaans. A combination of back translation, the committee approach and pre-test procedures (Brislin, 1980; Haupt, 2001; Retief, 1988) was followed. Six translators were used to translate the words and phrases into Afrikaans. All the translators were familiar with both languages and had previously translated different items between the two languages. One translator was a mother-tongue speaker of English, while the other five were Afrikaans mother-tongue speakers. The final translations are presented in Table I.

\section{Table 1. Final translation of labels}

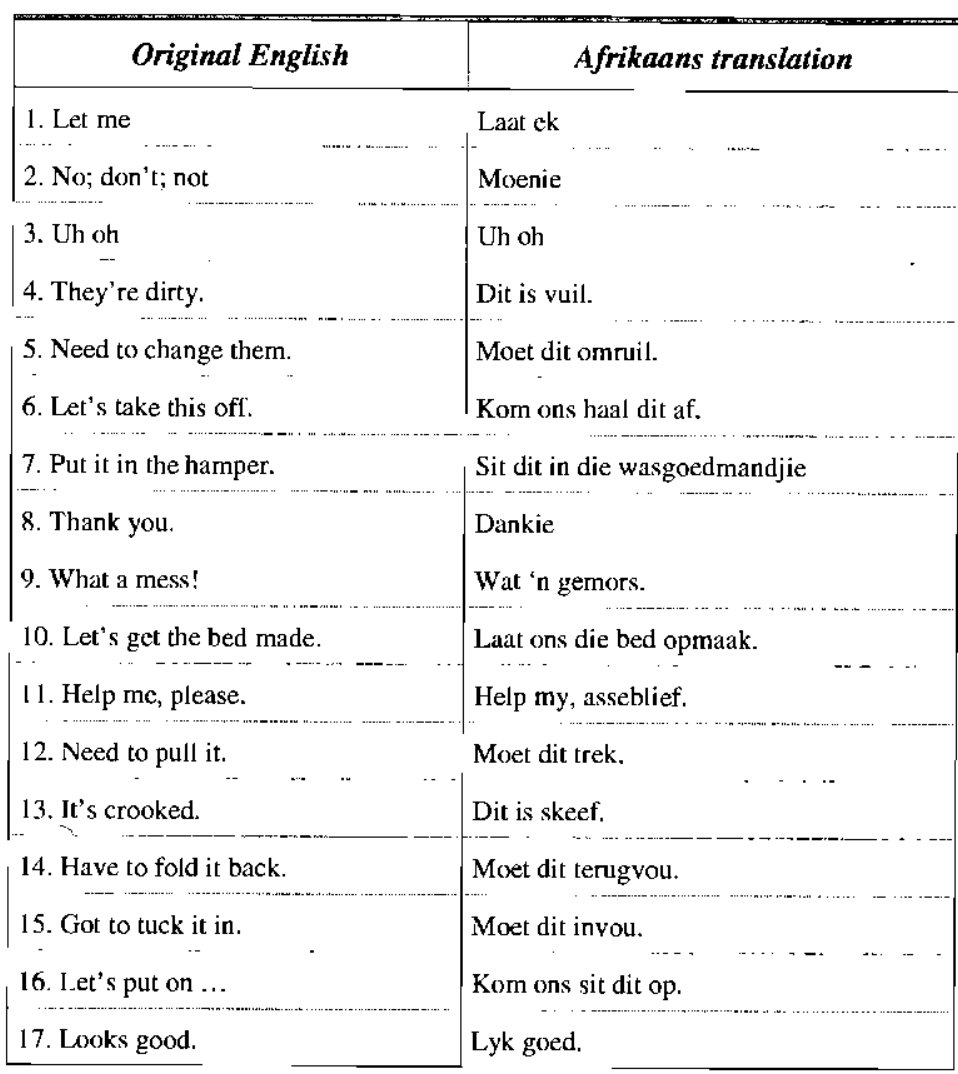

\section{Teaching material}

The training material consisted of the test overlay and 16 flash cards, with one symbol (size: $12 \times 18 \mathrm{~cm}$ ) placed on each A4 card. The symbols, their labels and the explanations (Afrikaans and English) used during training are presented in Appendix A. A pre-school teacher from the pilot school checked the appropriacy of the explanations to ensure familiarity to the age group.

\section{PROCEDURE}

The study was divided into two phases, the preparatory phase during which preparations essential for the execution of the main study were done and the main study itself. During the preparatory phase permission was obtained from the Free State Department of Education to conduct the study in their jurisdiction; consent forms, the test overlay, the pre-test overlay and the training material were compiled, the phrases were translated into Afrikaans and a pilot study of the test protocol and training method was executed. Ethics approval was obtained through the Ethics Committee at the University of Pretoria. Permission was obtained from each participating school's principal. The information letters sent out to the parents also requested written consent.

\section{Pilot study}

The pilot study was conducted to ensure the feasibility of the planned data collection as well as the suitability of the test material and the test protocol (Haupt, 2001; McMillan \& Schumacher, 2001). The pilot study was performed on 16 participants, who met the selection criteria, but who were not in cluded in the main study. Based on the results, small changes were made with regard to the test protocol and selection criteria. During day 1 of the pilot study, the researcher was unable to manage the group. They did not produce their own work, turned pages without the prompt or more than one page at a time, and indicated more than one symbol per page. A research assistant was appointed to help manage the group and the seating arrangement during the testing procedures was changed to create a private working space for each participant. The pilot study results indicated that the initial selection of criteria both parents being Afrikaans-speakers and participants being in a pre-school environment for at least a year, would eliminate suitable participants. These criteria were changed to one parent being an Afrikaansspeaker, and enrollment in pre-school from the beginning of the academic year.

\section{Data collection}

The data collection was completed within 40 days. Each school was visited three times on consecutive days. The 46 participants were divided into two cohorts that remained the same for the pre- and post-test. On day two, participants in the cohorts were randomly divided into experimental and control groups, with each group consisting of participants of both cohorts. This division was done to ensure that the different testing sessions would not influence the test results, as participants from the experimental and control groups would be represented in all the test procedures Sessions were conducted with eight or less participants at a time. On the first day, all participants had the pretest. On the second day only the experimental group received training. On the third day, both groups took the post-test.

During the pre- and post-test, the participants were each issued with a recording booklet, a blank page and a marker. Each booklet contained sixteen copies of the test-overlay and eight copies of the pre-test-training overlay. Each participant was given a number, so the pre- and post-test results could be linked and the privacy of the participant ensured. The resiearcher instructed the participants on how to make a cross with opportunities provided to practice this on a blank page. Participants then had eight trials in which they were asked to select the picture on the overlay that corresponded with the Afrikaans word read out by the researcher. The participants were guided on how to visually scan the matrix before choosing the picture. Participants were not corrected if they indicated the wrong picture.

For the test, the participants were asked to indicate with a cross the PCS symbol they thought matched the Afrikaans label, which was read out three times. The process was not timed. The labels were read in random order, drawn from a hat before the study commenced. The researcher and research assistant provided assistance if a participant seemed unsure, of what to do. The assistance entailed pointing to each picture to facilitate scanning. The researcher and research assistant further ensured that participants chose one picture per page, turned one page at a time and produced independent results.

On the second day of data collection, each participant in the experimental group was given a copy of the test overlay. 
The researcher instructed them to look at the flash card she held up and then to point to the symbol on the overlay in front of them. The researcher then labeled each symbol's meaning as they moved along the overlay. Together with the label, an explanation of the meaning was also given. This was done according to the prescribed script. The symbols were trained in the order in which they appeared on the overlay. The training process was immediately repeated and the participants were allowed to repeat the meaning with the researcher. The explanations of the labels are presented in Appendix A.

\section{RESULTS AND DHSCUSSION}

The results of the study are described and discussed according to the aims. The first section describes the sources and management of missing data. Next the pre-test data for both the experimental and control groups are presented and discussed. Thereafter is the presentation of the post-test data for both groups followed by the learnability data. Finally, there is a comparison between current study's and Haupt and Alant's (2002) results.

\section{Missing data}

Of a total of $1472(16 \times 2 \times 46)$ possible responses, nine could not be used in the analysis. There were three sources of missing data: faulty page turns, no symbol indicated and deviations in indicating choice. Four of the missing responses resulted from deviations in indicating choice, four from no symbol indicated and one from a faulty page tum. The influence of the missing data was deemed negligible and it was omitted from the analysis.

\section{Pre-test results}

The first sub-aim was to determine the accuracy (percentage of correct selections) of participants' correct selection of the symbol in response to its spoken label, and represents the symbol's guessability. The pre-test results from the experi- mental and control groups were statistically compared using the Mann-Whitney T-test (Steyn, Smit \& Du Toit, 1989). No difference was found between the two groups' pre-test results ( $p$ $=.5413$ ). Both the experimental and control groups' pre-test results are presented in Table 2.

Doherty, Daniloff and Lloyd (1985), and Haupt and Alant (2002) used strict (iconicity value $>75 \%$ ) and lenient (iconicity value $>50 \%$ ) criteria to interpret the transparency of AmericanIndian gestures and the iconicity of PCS symbols respectively. Iconicity values can be defined as the number of participants who responded correctly to each item and represent each symbol's guessability (Haupt, 2001). The current study used a lenient criterion to determine iconicity and accuracy of the data.

Given the iconicity criterion of an accuracy score > $50 \%$, it can be seen from Table 2 that $25 \%$ of the symbols could be described as iconic for the experimental group. According to the set criterion, $31.25 \%$ of the symbols could be described as iconic for the control group.

Table 2 further presents a comparison between the experimental and control groups' pre-test data. As can be seen from Table 2, symbol 1 presented with the greatest difference, 38 percentage points, between the accuracy scores of the two groups. The rest of the symbols showed a difference of less than 20 percentage points. Although there are differences between the symbols' ranking in the groups, symbols $6,9,10$, and 16 were iconic for both groups. According to the set criterion of an accuracy score $>50 \%$ the control group presented with another iconic symbol (symbol 1). For both the experimental and control groups, symbol 7 had the lowest accuracy score.

\section{Post-test results}

The second sub-aim was to determine the accuracy with which the experimental and control groups could select the correct symbol in response to its spoken label, after the experimental group had had a training session. The experimental group's posttest data is given in Table 3. From Table 3 it is evident that $18.75 \%$ of the symbols had an accuracy score of $100 \%$.

Table 2. A comparison between the experimental and control groups' pre-test results

\begin{tabular}{|c|c|c|c|c|}
\hline $\begin{array}{l}\text { Symbol } \\
\text { number }\end{array}$ & English phrase & $\begin{array}{c}\text { Experimental groups' } \\
\text { accuracy score }\end{array}$ & $\begin{array}{l}\text { Control groups' } \\
\text { accuracy score }\end{array}$ & $\begin{array}{c}\text { Difference in } \\
\text { percentage points }\end{array}$ \\
\hline 1 & Let me. & $21 \%$ & $59 \%$ & 38 \\
\hline 2 & Let's take this off: & $8 \%$ & $18 \%$ & 10 \\
\hline 3 & Need to change them. & $25 \%$ & $9 \%$ & 16 \\
\hline 4 & It's crooked. & $29 \%$ & $36 \%$ & 7 \\
\hline 5 & No. & $42 \%$ & $45 \%$ & 3 \\
\hline 6 & Let's get the bed made. & $92 \%$ & $82 \%$ & 10 \\
\hline 7 & Looks good. & $4 \%$ & $0 \%$ & 4 \\
\hline 8 & Got to tuck it in. & $25 \%$ & $14 \%$ & 11 \\
\hline 9 & Uh oh & $83 \%$ & $73 \%$ & 10 \\
\hline 10 & Need to pull it. & $63 \%$ & $64 \%$ & 1 \\
\hline 11 & They're dirty. & $17 \%$ & $36 \%$ & 19 \\
\hline 12 & What a mess! & $43 \%$ & $40 \%$ & 2 \\
\hline 13 & Thank you. & $42 \%$ & $29 \%$ & 13 \\
\hline 14 & Help me please. & $13 \%$ & $27 \%$ & 14 \\
\hline 15 & Have to fold it back. & $26 \%$ & $23 \%$ & 3 \\
\hline 16 & Put it in the hamper. & $67 \%$ & $77 \%$ & 10 \\
\hline
\end{tabular}


Table 3. A comparison between the experimental and control groups' post-test results

\begin{tabular}{|c|c|c|c|c|}
\hline $\begin{array}{l}\text { Symbol } \\
\text { number }\end{array}$ & English phrase & $\begin{array}{l}\text { Experimental groups' } \\
\text { accuracy score }\end{array}$ & $\begin{array}{l}\text { Control groups' } \\
\text { accuracy score }\end{array}$ & $\begin{array}{c}\text { Difference in } \\
\text { percentage points }\end{array}$ \\
\hline 1 & Let me. & $75 \%$ & $57 \%$ & 18 \\
\hline 2 & Let's take this off. & $63 \%$ & $5 \%$ & 58 \\
\hline 3 & Need to change them. & $71 \%$ & $18 \%$ & 53 \\
\hline 4 & It's crooked. & $75 \%$ & $36 \%$ & 39 \\
\hline 5 & No. & $75 \%$ & $55 \%$ & 20 \\
\hline 6 & Let's get the bed made. & $100 \%$ & $86 \%$ & 14 \\
\hline 7 & Looks good. & $54 \%$ & $9 \%$ & 45 \\
\hline 8 & Got to tuck it in. & $57 \%$ & $18 \%$ & 39 \\
\hline 9 & Uh oh & $100 \%$ & $91 \%$ & 9 \\
\hline 10 & Need to pull it. & $92 \%$ & $77 \%$ & 15 \\
\hline 11 & They're dirty. & $71 \%$ & $36 \%$ & 36 \\
\hline 12 & What a mess! & $91 \%$ & $73 \%$ & 18 \\
\hline 13 & Thank you. & $67 \%$ & $18 \%$ & 49 \\
\hline 14 & Help me please. & $88 \%$ & $14 \%$ & 74 \\
\hline 15 & Have to fold it back. & $54 \%$ & $32 \%$ & 22 \\
\hline 16 & Put it in the hamper. & $100 \%$ & $95 \%$ & 5 \\
\hline
\end{tabular}

The remaining $81.25 \%$ of the symbols all had an accuracy score of $>50 \%$.

The control group's post-test data is also presented in Table 3. From the table it can be seen that $43.75 \%$ of the symbols had an accuracy score of $>50 \%$. The rest of the symbols (56.25\%) had an accuracy score of $<50 \%$.

\section{Experimental group: pre- versus post-test results}

The experimental group's pre- and post-test means were statistically compared, using the Wilcoxon T-test (Steyn et al, 1989). The results showed a significant difference $(p<.0001)$, indicating an improvement in the accuracy with which participants correctly selected a symbol in response to its label after the single training session.
All four of the previously classified iconic symbols had a posttest accuracy score $\geq 92 \%$. These results seem to support the iconicity theory (Fuller, \& Lloyd, 1979) with the four symbols with the highest pre-test accuracy scores also having the highest posttest accuracy scores.

The percentage point differences between the experimental group's pre-test and post-test accuracy scores are presented in Table 4. From Table 4 it is evident that $68.75 \%$ of the symbols had an improvement of $>30$ percentage points, $25 \%$ of the symbols had an improvement of between 10 and 30 percentage points, while $6.25 \%$ had an improvement of $<10$ percentage points. Of the five symbols with a percentage point difference < 30 , two symbols (symbols 6 and 9) did not improve further. The other three symbols' percentage point difference were $\geq 25$ percentage points.

Table 4. The percentage point differences between the experimental and control groups pre-test and post-test accuracy scores

\begin{tabular}{|c|c|c|c|}
\hline $\begin{array}{l}\text { Symbol } \\
\text { number }\end{array}$ & English phrase & $\begin{array}{l}\text { Percentage point difference between the experi- } \\
\text { mental group's pre- and post-test accuracy scores. }\end{array}$ & $\begin{array}{l}\text { Percentage point difference between the con- } \\
\text { trol gtoup's pre- and post-test accuracy scores. }\end{array}$ \\
\hline 1 & Let me. & 54 & 2 \\
\hline 2 & Let's take this off. & 55 & 13 \\
\hline 3 & Need to change them. & 46 & 9 \\
\hline 4 & It's crooked. & 46 & 0 \\
\hline 5 & No. & 33 & 10 \\
\hline 6 & Let's get the bed made. & 8 & 4 \\
\hline 7 & Looks good. & 50 & 9 \\
\hline 8 & Got to tuck it in. & 32 & 4 \\
\hline 9 & Uh oh & 17 & 18 \\
\hline .10 & Need to pull it. & 29 & 13 \\
\hline 11 & They're dirty. & 54 & 0 \\
\hline 12 & What a mess! & 48 & 33 \\
\hline 13 & Thank you. & 25 & 11 \\
\hline 14 & Help me please. & 75 & 13 \\
\hline 15 & Have to fold it back. & 28 & 9 \\
\hline 16 & Put it in the hamper. & 33 & 18 \\
\hline
\end{tabular}

Die Suid-Afrikaanse Tydskrif vir Kommunikasieafwykings, Vol. 52, 2005 


\section{Control group: pre- versus post-test results}

The control group's pre-and post-test means were also statistically compared with the Wilcoxon T-test (Steyn et al., 1989). Although the participants did not receive any training, a significant difference was found $(\mathrm{p}=.0446)$, indicating an improvement in the accuracy with which participants correctly selected a symbol in response to its label. In comparison with the difference calculated for the experimental group, this might be seen as only a slight improvement in accuracy, but this could mean that the single exposure through the pre-test procedure did lead to recognition of more symbols during the pot-test procedure.

The percentage point difference between the control group's pre-test and post-test accuracy scores are also presented in Table 3. When examining the data in Table 3 it is evident that $6.25 \%$ of the symbols (one symbol) had a difference of $>30$ percentage points, $37.5 \%$ of the symbols had a percentage point difference between 10 and 30 percentage points, while $56.25 \%$ of the symbols had a percentage point difference $<10$ percentage points.

\section{Interpretation of results}

No significant differences existed between the two groups' pre-test results and each group performed significantly better on the post-test. The differences in accuracy scores, as determined by the pre- and post-test performance for each group was statistically analysed using the Mann-Whitney T-test (Steyn et al., 1989). A statistical difference was present $(\mathrm{p}<.0001)$.

The percentage point difference between the experimental and control groups' post-test accuracy scores were calculated and is presented in Table 4 . From Table 4 it is evident that $50 \%$ of the symbols presented with a percentage point difference of $>30$ percentage points between the two groups' post-test results in contrast to the $6.25 \%$ of the symbols which presented with $>30$ percentage points during the pre-test procedure (see Table 4). A third $(37.5 \%)$ of the symbols presented with a difference of between 10 and 30 percentage points and $12.55 \%$ of the symbols presented with a percentage point difference of $<10$ percentage points, in contrast with the $56.25 \%$ of the symbols with such a difference during the pre-test comparison.

These results confirm the fact that the experimental group benefited from the single training session and was able to remember the symbols easily. The improved performance in the posttest results of the experimental group was expected and may be attributed to the single training session, as well as the earlier exposure to the symbols through the pre-test procedure. The better performance in the post-test results of the control group was not anticipated, but its occurrence may be explained by the single exposure the participants had to the symbols during the pre-test procedure.

\section{Comparison with a similar study}

The iconicity section of the study is similar to that of Haupt and Alant (2002), where the iconicity of 36 PCS presented on a commercially available communication overlay was investigated. The participants in their study were 10-year-old Zuluspeaking children living in the rural areas of Kwa-Zulu Natal.

Care must be taken when comparing the results of the current study with the results obtained by Haupt (2001). The number of variables that differ between the two studies makes it almost impossible to compare these studies. It is, however, possible to examine the data from both studies and discuss differences and similarities. (The symbols will be numbered according to the numbers of the current study). The combined pre-test data of the current study and the results of the study by Haupt and Alant are (2002) presented in Table 5.

For the current study four symbols $(6,9,16$ and 10$)$ can be classified as iconic. Three of the symbols $(10,6$ and 16) used in the study by Haupt and Alant (2002) can be classified as iconic, when using the same criterion (accuracy score $>50 \%$ ). For both studies, symbol 7 had the lowest accuracy score. With the exception of symbols 10 and 14 , the individual symbols in the current study had higher accuracy scores than the same symbols in the study by Haupt and Alant (2002). The percentage point differences between the current study and Haupt and Alant's (2002) are presented in Table 5.

Table,5. A comparison between Basson and Alant and Haupt and Alant's (2002) results.

\begin{tabular}{|c|c|c|c|c|}
\hline Symbol number & English phrase & Basson \& Alant & Haupt \& Alant & $\begin{array}{c}\text { Difference in } \\
\text { percentage points }\end{array}$ \\
\hline 1 & Let me. ! & - $39 \%$ & $3 \%$ & 36 \\
\hline 2 & Let's take this off. & $13 \%$ & $8 \%$ & 5 \\
\hline 3 & Need to change them. & $17 \%$ & $16 \%$ & 1 \\
\hline 4 & It's crooked. & $33 \%$ & $13 \%$ & 20 \\
\hline 5 & No. & $43 \%$ & $0 \%$ & 43 \\
\hline 6 & Let's get the bed made. & $87 \%$ & $67 \%$ & 20 \\
\hline 7 & Looks good. & $2 \%$ & $0 \%$ & 2 \\
\hline 8 & Got to tuck it in. & $20 \%$ & $17 \%$ & 3 \\
\hline 9 & Uh oh & $78 \%$ & $46 \%$ & 32 \\
\hline 10 & Need to pull it. & $63 \%$ & $81 \%$ & 18 \\
\hline 11 & They're dirty. & $27 \%$ & $3 \%$ & 24 \\
\hline 12 & What a mess! & $42 \%$ & $14 \%$ & 28 \\
\hline 13 & Thank you. & $36 \%$ & $9 \%$ & 27 \\
\hline 14 & Help me please. & $20 \%$ & $47 \%$ & 27 \\
\hline 15 & Have to fold it back. & $24 \%$ & $2 \%$ & 22 \\
\hline 16 & Put it in the hamper. & $72 \%$ & $57 \%$ & 15 \\
\hline
\end{tabular}


From Table 5 it is evident that symbol 1 showed a percentage point difference of 36 . Although the combined pretest results from the current study indicate that the participants did not find this symbol iconic, the participants of the current study might have seen it as more iconic than the participants of Haupt and Alant's (2002) study.

Symbol 5 showed the greatest difference (a difference of 43 percentage points) between the data of the two studies. Although once again the participants of the current study did not find the symbol 'no' iconic, they appeared to find it more iconic than the participants in Haupt and Alant's (2002) study. It could be that the participants in the current study were able to use the cue given by the arrows better than did the participants of the Haupt's study. The participants of the current study may have had more experiences with books, computers and television, which might have led to them understanding this symbol better, although they were younger than the participants in Haupt's study.

For participants in both studies symbol 2 ('let us take it off') was not iconic. It seems that neither of the two studies' participants were able to use the cue given by the arrow as taking something off.

For both studies, symbol 7 ('it looks good') was the least iconic symbol. The fact that symbol 7 was the least iconic symbol could be due to the fact that the sign from which this symbol is derived is unknown in the South African context, a thumbs up sign would probably have been a better choice.

\section{Use of arrows}

Haupt and Alant (2002) mentioned that a factor that could have contributed to the low iconicity in the Haupt (2001) sample population, was the presence of arrows in many of the symbols. They recommended that clinicians be aware that special training might be needed in the use of arrows. The current study had similar results, in that all the symbols with arrows, had a pre-test accuracy score of less than 50\%. During the training process, experimental group participants' attention were drawn to the arrows and they were led to use the arrow as part of their strategy to link the symbol and its meaning. After training, three symbols of the seven symbols with arrows had an experimental post-test accuracy score of more than $70 \%$, two an experimental post-test accuracy score of more than $60 \%$ and the remaining two an experimental post-test accuracy score of more than $50 \%$. The results seem to support Haupt and Alant's (2002) conclusion that training is needed in the use of arrows.

In the control group, only one (symbol 5) of the seven symbols with arrows had a post-test accuracy score of more than $50 \%$. Symbol 4's accuracy score stayed the same; while symbols' 2 and 13's post-test accuracy scores were less than their pre-test accuracy scores. It seems that the pre-test exposure did not give the participants enough information to help them make better use of the cues afforded by the arrows.

\section{CONCLUSION}

The current study took a step further in obtaining culturespecific iconicity information in the South African context. The study also investigated the learnability of PCS symbols after a single training session.

The results of the study suggested that the 16 PCS symbols had an iconicity of between 12.5 and $25 \%$ for Afrikaans speaking 6-year olds participating in the study. A similar study found that 36 PCS had an iconicity of between 2.8 and $11.1 \%$ for a group of Zulu-speaking 10-year olds (Haupt, 2001; Haupt \& Alant, 2002). Both these studies suggest that even though PCS may be seen as one of the most iconic symbol sets, there cannot be an assumption that it will be equally guessable for all populations.

The results secondly showed an improvement in the posttest results of both experimental and control groups. The significant difference between the post-test results of both groups does, however, indicate that the experimental group recognized more symbols during the post-test than the control group and benefited from the single training session in that they and were able to use the explanations to help them remember the symbols' meanings. The control group did not receive training, but a significant difference was found between pre- and post-results. This finding can be attributed to the single exposure the participants had to the symbols and labels during the pre-test procedure.

Although the results of the current study could not be statistically compared with a similar study (Haupt, 2001), as too many variables differed (age and culture of the participants as well as overlay size), descriptive comparisons reveal the following: Differences between the two studies could be a reflection of the different cultural experiences of the two groups.

It seems as if the participants of the current study made use of the information afforded them by the postural cues implying motion. They did not, however, make full use of the arrow cues or the direction of the arrows, which also implied motion. This correlates with observations from Haupt (2001), Haupt and Alant (2002) and Moolman and Alant (1997). Once the participants in the experimental group were made aware of the arrows, they seemed to use the information the arrows offered to help them remember the symbol meanings during the post-test procedure.

The results of the current study support previous research on the rather low percentage of PCS symbols that can be correctly identified on first exposure. It also indicates differences between children from different cultural backgrounds and exposure (Basson, 2004; Haupt \& Alant 2002). The relatively small participant sample ( $n=46$ ) as well as the small number of symbols (16) can be seen as two limitations of the study. Similarly, the use of a communication board with a specific theme may limit the generalizability of the iconicity values to the same symbols in other contexts. As the participants were typically developing children, the application of this data to children with disabilities is limited. The study does, however, provide some important information on first exposure and learning of PCS symbols.

More research is needed in this area using different PCS symbols (thematically organized as well as random symbols), different grid sizes, different age and culture groups and different training strategies. It would also be beneficial to have typically developing as well as participants with disabilities.

\section{ACKNOWLEDGEMENTS}

This article is based on a study conducted by the first author under supervision of the second author, in partial fulfilment of the requirements for a Master's degree in AAC. The authors would like to thank the teachers, learners and parents who took part in the study. The help of Mrs R. Owen and Dr. L. Louw with the statistical processing of the data is also gratefully acknowledged. 


\section{REFERENCES}

Basson, H.M. (2004). The iconicity and learnability of picture communication symbols: A study on Afrikaans-speaking children. Unpublished master's thesis. University of Pretoria, Pretoria, Gauteng, South Africa.

Blischak, D.M., Lloyd, L.L., \& Fuller, D.R. (1997). Terminology issues. In L.L. Lloyd, D.R. Fuller, \& H.H. Arvidson (Eds.), Augmentative and alternative communication. A handbook of principles and practices (pp. 38-42). Boston: Allyn \& Bacon Inc.

Brislin, R.W. (1980). Translation and content analysis of oral and written materials. In H.C. Triandis, \& J.W. Berry (Eds.), Handbook of cross-cultural psychology: Vol 2. Methodology (pp. 389-444). Boston: Allyn \& Bacon Inc.

Clark, C. (1981). Learning words using traditional orthography and the symbols of Rebus, Bliss and Carrier. Journal of Speech and Hearing Disorders, 46, 191-196.

DeLoache, J.S. (1991). Symbolic functioning in very young children's understanding of pictures and models. Child Development, 62, 736-752.

Deregowski, J.B. (1980). Perception. In H.C. Triandes, \& W. Lonner (Eds.), Handbook of cross-cultural psychology. Vol 3: Basic processes (pp. 21-115). Boston: Allyn \& Bycon.

Doherty, J.E., Daniloff, J.K., \& Lloyd, L.L. (1985). The effect of categorical presentation on Amer-Ind transparency. Augmentative and Alternative Communication, 1, 10 - 16.

Duncan, H.F., Gourlay, N., \& Hudson, W. (1973). A study of pictorial perception among Bantu and white primary school children in South Africa. (Human Sciences Research Council Publication No. 31). Johannesburg, South Africa: Witwatersrand University Press.

Elder, P. S., \& Goossens, C. (1996). Communication overlays for engineering training environments. Overlays for adolescents and adults who are moderately/severely developmentally delayed. Solana Beach, CA: Mayer-Johnson Co.

Fristoe, M., \& Lloyd, L.L. (1979). Nonspeech communication. In N.R. Ellis (Ed.), Handbook of mental deficiency: Psychological theory and research (2 $2^{\text {nd }}$ ed., pp. 401-430). New York; Lawrence Erlbaum Associates.

Fuller, D.R., \& Lloyd, L.L. (1991). Towards common usage of iconicity terminology. Augmentative and Alternative Communication, 7, 215-220.

Fuller, D.R., \& Lloyd, L.L. (1997). Symbol selection. In L.L. Lloyd, D.R. Fuller, \& H.H. Arvidson (Eds.). Augmentative and alternative communication. A handbook of principles and practices (pp. 214-225). Boston: Allyn \& Bacon Inc.

Fuller, D.R., \& Stratton, M.M. (1991). Representativeness versus translucency: Different theoretical backgrounds, but are they really different concepts? A position paper. Augmentative and Alternative Communication, 7, 51 - 58 .
Haupt, L. (2001). The iconicity of selected picture communication symbols for rural Zulu-speaking children. Unpublished master's thesis. University of Pretoria, Pretoria, Gauteng, South Africa:

Haupt, L., \& Alant, E. (2002). The iconicity of selected picture communication symbols for rural Zulu-speaking children. The South African Journal of Communication Disorders, 49, $40-49$.

Huer, M.B. (2000). Examining perceptions of graphic symbols across cultures: preliminary study of the impact of culture/ ethnicity. Augmentative and Alternative Communication, 16, 180-185.

Huer, M.B., \& Saenz, T.I. (2002). Thinking about conducting culturally sensitive research in augmentative and alternative communication. Augmentative and Alternative Communication, 18, $267-273$.

Martlew, M., \& Connolly, K.L. (1996). Human figure drawings by schooled and unschooled children in Papua New Guinea. Child Development, 67, 2743-2762.

McMillan, J.H., \& Schumacher, S. (2001). Research in Education. A conceptual introduction ( $5^{\text {th }}$ ed.). New York: Longman.

Miller, R.J. (1973). Cross-cultural research in the perception of pictorial materials. Psychological Bulletin, 2, 135-150.

Mizuko, M. (1987). Transparency and ease of learning of symbols represented by Blissymbols, PCS, and Picsyms. Augmentative and Alternative Communication, 3, 129-136.

Mizuko, M., \& Reichle, J. (1989). Transparency and recall of symbols among intellectually handicapped adults. Journal of Speech and Hearing Disorders, 54, 627-633.

Moolman, E., \& Alant, E. (1997). The teaching of Blissymbols as a bridge into literacy for children with cognitive impairments: A comparison of two training approaches. The South African Journal of Communication Disorders, 44 , $73-86$.

Orkin, F.M. (1998). Census in brief. Retrieved October 28, 2002, from http://www.statssa.gov.za/ RelatedInverseSites/census96/HTML/CIB/about.htm

Retief, A. (1988). Method and theory in cross-cultural psychological assessment. (Investigation into research methodology (Human Sciences Research Council Publication No. 31). Pretoria, South Africa.

Stephenson, J., \& Linfoot, $\mathbb{K}$. (1996). Pictures as communication symbols for students with severe intellectual disability. Augmentative and Alternative Communication, 12(4), 244-255

Steyn, A.G.W., Smit, C.F., \& $\mathbb{D}$ u Toit, S.IH.C. (1989). Moderne statistiek vir die praktyk. Pretoria: Van Schaik. 


\begin{tabular}{|c|c|c|}
\hline Symbol & Explanation: English & Explanation: Afrikaans \\
\hline & $\begin{array}{l}\text { This picture means: LET ME. } \\
\text { Look, he points to himself and says: "LET ME." }\end{array}$ & $\begin{array}{l}\text { Hierdie prentjie beteken: LAAT EK } \\
\text { Kyk, die mannetjie wys na homself en sê "LAAT EK" }\end{array}$ \\
\hline & $\begin{array}{l}\text { This picture means: LET'S TAKE THIS OFF. } \\
\text { Look, he is taking off his hat and says: "LET'S TAKE } \\
\text { THIS OFF." }\end{array}$ & $\begin{array}{l}\text { Hierdie prentjie beteken: KOM ONS HAAL DIT AF } \\
\text { Kyk, die mannetjie haal sy hoed af en sê: "KOM ONS HAAL } \\
\text { DIT AF" }\end{array}$ \\
\hline & $\begin{array}{l}\text { This picture means: NEED TO CHANGE THEM. } \\
\text { Look, it changes. "NEED TO CHANGE THEM." }\end{array}$ & $\begin{array}{l}\text { Hierdie prentjie beteken: MOET DIT OMRULL } \\
\text { Kyk, dit verander. Ons "MOET DIT OMRUIL" }\end{array}$ \\
\hline & $\begin{array}{l}\text { This picture means: IT'S CROOKED. } \\
\text { Look one of the sticks is crooked: "IT'S CROOKED." }\end{array}$ & $\begin{array}{l}\text { Hierdie prentjie beteken: DIT IS SKEEF } \\
\mathrm{Kyk} \text {, die een stokkie is skeef. "DIT IS SKEEF" }\end{array}$ \\
\hline & $\begin{array}{l}\text { This picture means: NO } \\
\text { Look, the man shakes his head and says: "NO." }\end{array}$ & $\begin{array}{l}\text { Hierdie prentjie beteken: MOENIE. } \\
\text { Kyk, die mannetjie skud sy kop en sê: "MOENIE" }\end{array}$ \\
\hline & $\begin{array}{l}\text { This picture means: LET'S GET THE BED MADE. } \\
\text { Look, he is making his bed and says: "LET'S GET } \\
\text { THE BED MADE." }\end{array}$ & $\begin{array}{l}\text { Hierdie prentjie beteken: LAAT ONS DIE BED OPMAAK } \\
\text { Kyk, die mannetjie maak die bed bed op, hy sê "LAAT ONS DIE } \\
\text { BED OPMAAK" }\end{array}$ \\
\hline & $\begin{array}{l}\text { This picture means: LOOKS GOOD. } \\
\text { Look, the hand shows: "LOOKS GOOD." }\end{array}$ & $\begin{array}{l}\text { Hierdie prentjie beteken: LYK GOED } \\
\text { Kyk, die hand wys: "LYK GOED" }\end{array}$ \\
\hline & $\begin{array}{l}\text { This picture means: GOT TO TUCK IT IN. } \\
\text { Look, the arrow points inside: " GOT TO TUCK IT } \\
\text { IN." }\end{array}$ & $\begin{array}{l}\text { Hierdie prentjie beteken: MOET DIT INVOU } \\
\text { Kyk die pyltjie wys in. "MOET DIT INVOU" }\end{array}$ \\
\hline & $\begin{array}{l}\text { This picture means: UH-OH. } \\
\text { Look, he widens his eyes and mouth and says: "UH- } \\
\text { OH." }\end{array}$ & $\begin{array}{l}\text { Hierdie prentjie beteken: UH-OH } \\
\text { Kyk, die mannetjie trek sy oë en mond groot oop en sê: "UH- } \\
\text { OH" }\end{array}$ \\
\hline & $\begin{array}{l}\text { This picture means: NEED TO PULL IT. } \\
\text { Look, he is pulling the rock and says: "NEED TO } \\
\text { PULL IT." }\end{array}$ & $\begin{array}{l}\text { Hierdie prentjie beteken: MOET DIT TREK } \\
\text { Kyk, die mannetjie trek die klip, hy sê "MOET DIT TREK" }\end{array}$ \\
\hline & $\begin{array}{l}\text { This picture means: THEY'RE DIRTY. } \\
\text { Look at the dirty spots: "THEY'RE DIRTY. }\end{array}$ & $\begin{array}{l}\text { Hierdie prentjie beteken: DIT IS VUIL } \\
\text { Kyk, daar is vuil kolletjies op. "DIT IS VUIL" }\end{array}$ \\
\hline & $\begin{array}{l}\text { This picture means: WHAT A MESS! } \\
\text { Look, somebody overturned the paint: "WHAT A } \\
\text { MESS!" }\end{array}$ & $\begin{array}{l}\text { Hierdie prentjie beteken: WAT 'N GEMORS! } \\
\text { Kyk, iemand het die verf omgestamp: "WAT 'N GEMORS!" }\end{array}$ \\
\hline & $\begin{array}{l}\text { This picture means: THANK YOU. } \\
\text { Look, the man points with his hands: "THANK YOU." }\end{array}$ & $\begin{array}{l}\text { Hierdie prentjie beteken: DANKIE } \\
\text { Kyk, die mannetjie wys met sy hande: "DANKIE" }\end{array}$ \\
\hline & $\begin{array}{l}\text { This picture means: HELP ME, PLEASE. } \\
\text { Look, the one hand helps the other hand: "HELP ME, } \\
\text { PLEASE." }\end{array}$ & $\begin{array}{l}\text { Hierdie prentjie beteken: HELP MY ASSEBLIEF } \\
\text { Kyk, die een hand help die ander hand. "HELP MY } \\
\text { ASSEBLIEF" }\end{array}$ \\
\hline & $\begin{array}{l}\text { This picture means: HAVE TO FOLD IT BACK. } \\
\text { Look, they fold back the page: "HAVE TO FOLD IT } \\
\text { BACK." }\end{array}$ & $\begin{array}{l}\text { Hierdie prentjie beteken: MOET DIT TERUGVOU } \\
\text { Kyk hierdie papier word teruggevou. "MOET DIT } \\
\text { TERUGVOU" }\end{array}$ \\
\hline & $\begin{array}{l}\text { This picture means: PUT IT IN THE HAMPER. } \\
\text { Look, all the washing is in the hamper: "PUT IT IN } \\
\text { THE HAMPER." }\end{array}$ & $\begin{array}{l}\text { Hierdie prentjie beteken: SIT DIT IN DIE } \\
\text { WASGOEDMANDJIE } \\
\text { Kyk, die wasgoed is in die wasgoedmandjie. "SIT DIT IN DIE } \\
\text { WASGOEDMANDJIE" }\end{array}$ \\
\hline
\end{tabular}




\begin{tabular}{||ll|}
\hline Centre for & Sentrum vir \\
Augmentative and & Aanvullende en \\
Alternative & Alternatiewe \\
Communication & Konmunikasie \\
& \multicolumn{2}{c|}{ \& } \\
& INIERFACE \\
\hline
\end{tabular}

$2004 T$-Systems Age of Innovation \& Sustainability. Awards: Excellence in Innovation and Sustainability: Social

2003 National Science \& Technology Awards: Corporate Organization over the last ten years.

2002: Shilley McNaughton Award for Exemolary Communication received from the Intemational Society for Augmentative and Altemative Communication

1998: Folex Award for Enterprise: Associate Laureate

1995: Education Africa Presidential Award for Special Needs

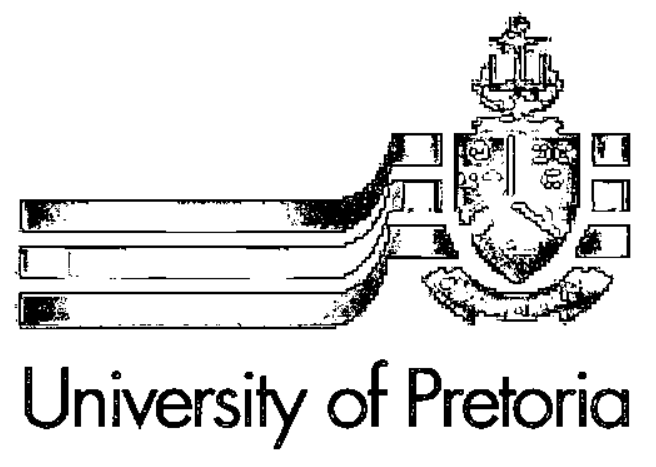

website: http://www.up.ac.za/acadenic/caac

Fax/Faks: (012) 420 -4389

Tel: (012) 420-2001

Ermail: ernaalant@upac.za

Faculty of Education/ Fakulteit Opvoedikunde

Centre for Augmentative and Alternative Connenanication Sentrum vir Aanvullende en Altennatiewe Komnnamiikasie University of Pretoria, Lynmwood Road

PRETORIA, 0002

SOUTHH AFRICA

Dear SASHLA member

\section{FURTHER STUDIES AT THE CENTRE FOR AUGMENTATIVE AND ALTERNATIVE COMMUNRCATION}

At the Centre for Augmentative and Alternative Communication, we believe that studying need not be an isolated experience. We have fifteen years experience in running distance postgraduate courses. Our strength lies in being able to support our students in distance studies while simultaneously providing locally and internationally recognized qualifications. The closing date for applications is 31 January 2005. Feel free to browse our website for more information about the Centre for AAC and its activities: www.up.ac.za/academic/caac.

(i) For more specific information about our Master degree in ECI please visit the following web-page http://www.caac. up.ac.za/pages/activities/masterseci.html or contact Dr Kitty Uys at kitty.uys@ up.ac.za

(i) For more specific information about our Master degree in AAC please visit the following web-page http://www.caac. up.ac.za/pages/activities/masters.html or contact MAAAC@postino.up.ac.za

(i) For more specific information about our Honours in AAC please visit the following web-page http://www.caac.up.ac. za/pages/activities/honours.html or contact Miss Michal Harty at Michal.harty@up.ac.za

We are most keen to strengthen the infrastructure of knowledge and skills in our country in relation to working with children and adults with severe disabilities and little or no functional speech. Please look at these courses - and see if you don't become inspired to join us in this venture!! Achievement bursaries are available for various degrees and are dependant on your marks. A sub minimum of $60 \%$ is required to qualify for an achievement bursary. Application forms will be available from 30 October 2005 with the closing date being 31 January 2006. Contact Elna van der Walt (012) 4205111 . For further information regarding course fees and bursaries contact the client service centre at (012) 4204111.

We would love to have you on board! We look forward to hearing from you.

Kind regards,

Prof. E. Alant

Director: CAAC

17 October 2005 